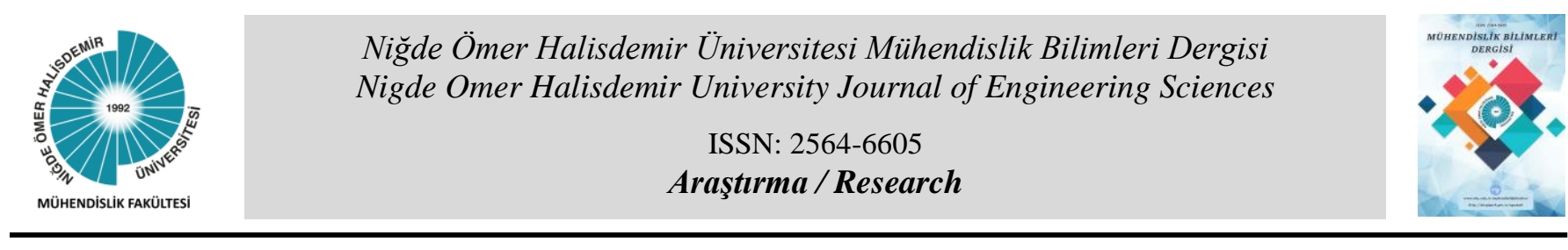

\title{
GERİ KAZANILMIŞ ATIKSULARIN YEŞIL ALAN SULAMASINDA KULLANIMI
}

\author{
Serdar KOYUNCU1(D), Sema ARIMAN²*iD \\ ${ }^{I}$ Konya Büyükşehir Belediyesi, Konya, Turkey \\ ${ }^{2}$ Samsun Üniversitesi, Meteoroloji Mühendisliği Bölümü, Samsun, Türkiye
}

\begin{abstract}
ÖZET
$\mathrm{Bu}$ çalışmanın amacı, kentsel atıksuyun ileri arıtma teknolojisiyle geri kazanımı ve arııılmış atıksuların yeşil alanların sulamasında yeniden kullanımının belirlenmesidir. Bu kapsamda, Konya İleri Biyolojik Atıksu Arıtma Tesisinden deşarj edilen arıtılmış atıksuların yeşil alan sulamasında kullanılması amacıyla, $3.600 \mathrm{~m}^{3} /$ gün kapasiteli gerçek ölçekli atıksu geri kazanımı tesisinin performansı izlenmiştir. Gerçek ölçekli ileri Atıksu Geri Kazanım Tesisinde; temel kontrol parametreleri olan pH, AKM, BOİ, bulanıklık, Fekal Koliform ve bakiye klor parametreleri belirlenmiştir. Atıksu geri kazanım tesis girişindeki kirletici

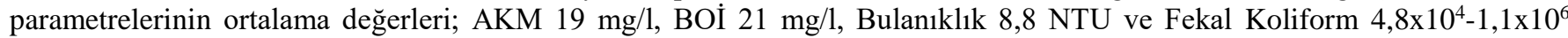
adet/100 ml aralığında ölçülmüştür. Geri kazanılarak elde edilen sulama suyunda ise pH 7,7, AKM $9 \mathrm{mg} / 1$, BOİ $10 \mathrm{mg} / \mathrm{l}$, Bulanıklık 3,4 NTU, Fekal Koliform 0 adet/100 ml ve Bakiye Klor 0,6 mg/l olarak belirlenmiştir. Atıksu Arıtma Tesisleri Teknik Usuller Tebliğine göre; B sınıfı sulama suyu kriterlerinin sürekli sağlandığı görülmüş ve yönetmelikte belirtilen alanlarda yeşil alan sulaması için uygun bulunmuştur.
\end{abstract}

Anahtar kelimeler: İleri atıksu arıtma, Geri kazanım, Yeniden kullanım, Mor şebeke

\section{THE USE OF RECYCLED WASTE WATER FOR IRRIGATION OF GREEN AREAS}

\begin{abstract}
The aim of this study is to recycle the urban wastewater by advaced treatment technology and to determine the reuse of treated wastewater in the irrigation of green areas. In this context, the performance of a real-scale wastewater recovery plant with a capacity of 3,600 $\mathrm{m}^{3} / \mathrm{day}$ was monitored for a possible use of treated wastewater discharged from the Konya Advanced Biological Wastewater Treatment Plant for green area irrigation. In the study, the basic control parameters of a real scale advanced wastewater recycling plant, namely, pH, SSM, BOD, turbidity, Fecal Coliform and residual chlorine parameters were determined. The average values of pollutant parameters at the entrance of the wastewater recycle plant were measured as $19 \mathrm{mg} / \mathrm{l}$ (SSM), $21 \mathrm{mg} / \mathrm{l}$ (BOD), $8.8 \mathrm{NTU}$ (turbidity) and $4.8 \times 10^{4}-1.1 \times 10^{6}$ pieces $/ 100 \mathrm{ml}$ (Fecal Coliform). For the recycled irrigation water, these values were determined as $7.7(\mathrm{pH}), 9 \mathrm{mg} / \mathrm{l}(\mathrm{SSM}), 10 \mathrm{mg} / \mathrm{l}(\mathrm{BOD}), 3.4 \mathrm{NTU}$ (turbidity), 0 piece/100 ml (Fecal Coliform) and $0.6 \mathrm{mg} / \mathrm{l}$ (residual chlorine). According to the Technical Procedures of Wastewater Treatment Plants, it has been observed that B-class irrigation water criteria have been met consistently and it has been found suitable for green area irrigation in the areas specified in the regulation.
\end{abstract}

Keywords: Advanced wastewater, Recycling, Reuse, Purpal network

\section{GíRİş}

Su temini ve su kalitesinin bozulması, artan su talebi, aşırı olayların (firtına, sel, hortum,tayfun vs.) beklenmedik etkileri ve iklim değişkenliği/değişikliğinin etkileri yaşanan küresel kaygılar arasında yer almaktadır. Bu nedenle, dünya çapında, özellikle su kıtlığı olan ülkelerde, sınırlı kalitede su, tarımsal su kaynaklarının giderek daha önemli bir bileşeni haline gelmektedir [1]. Birleşmiş Milletler dünyadaki su rezervlerinin yalnızca \%2,5 oranındaki bir kısmının tatlı su kaynağı olduğunu ve 25 yıl içerisinde dünya nüfusunun üçte iki olan kısmının kuraklık çeken bölgelerde yaşamak zorunda kalacağını belirtmektedir [2].

* Sorumlu yazar / Corresponding author, e-posta / e-mail: sema.ariman @ samsun.edu.tr

Geliş / Recieved: 29.04.2019 Kabul/ Accepted: 22.11.2019 doi: 10.28948/ngumuh.559080 
Türkiye'nin durumu ise 2012 yılı itibari ile 122 milyar $\mathrm{m}^{3}$ olan su potansiyelinin \%39 unu kullanarak, bunun \%73'ünü tarımsal sulama amaçlı kullanmaktadır. Artan tarım alanları ve tarımsal sulama suyu ihtiyacının artması ile birlikte $72 \mathrm{milyar}^{3}$ su kullanımı ile birlikte tarımsal su kullanım oranını \%64'e indirilmesi hedeflenmektedir. Ülkemiz, 2013 yılı itibarıyla kişi başına düşen yaklaşık $1500 \mathrm{~m}^{3}$ kullanılabilir su miktarı ile su kısıtı bulunan ülkeler arasında yer almaktadır. 2030 yılında kişi başına düşen $1100 \mathrm{~m}^{3}$ kullanılabilir su miktarıyla, Türkiye su sıkıntısı çeken bir ülke durumuna gelebilecektir [3]. 1990-2025 yılları arasında su miktarındaki azalma oranının \%40 mertebesinde olması beklenmektedir [4]. Ülkemizde yeni tarım alanlarının sulamaya açılacak olması ve artan sanayi suyu talebi ile birlikte suya olan talep artacak ve arıtılmış atıksuların yeniden kullanımı daha da önem kazanacaktır.

Artan su talebine karşılık tatlı su kaynaklarını yenileyip miktarını artırmak teknik ve ekonomik açıdan sınırlayıcı olduğu için sürdürülebilir kalkınmayı sağlayabilecek değişik pratik çözümlere ihtiyaç bulunmaktadır. Bu durumda alternatif bir su kaynağı olarak arıtılmış atıksuların geri kazanılarak yeniden kullanımı gündeme gelmektedir. Dünyada atıksularını arıtarak geri kazanan ülkelerin başlıcaları; Amerika Birleşik Devletleri, Güney Afrika, İsrail, Güney Kıbrıs, Yunanistan, Ürdün, Kuveyt, Tunus, Mısır, Cezayir, Bahreyn, Birleşik Arap Emirlikleri, İran, Irak, Lübnan, Libya, Katar, Fas, Umman, Suudi Arabistan, Suriye, Namibya, Yemen, Tacikistan, Türkmenistan, Kırgızistan, Avustralya, Meksika, Arjantin, Sili, Brezilya, Belçika, Fransa, İtalya, Çin, Hindistan ve Japonya'dır. Suyun geri kazanımında artan eğilim; entegre su kaynakları yönetimi ve sürdürülebilir kalkınma için hayati bir bileşen olarak yalnızca kuraklık ve su sıkıntısı çeken bölgelerde değil; su kaynaklarının zengin olduğu bölgelerde de suyu geri kazanmak ve tatlı su kaynaklarına olan yönelimi azaltmaktır. Yüksek oranda yağış alan bölgelerde su temini taşıma ya da pompaj maliyetleri yüzünden zorlaşabilmekte, bu da atıksuların geri kazanılarak kullanılmasını, önemli bir su kaynağı olarak öne çıkarmaktadır [5].

Arıtılan atıksular çok çeşitli amaçlar için kullanılabilmektedir. Arıtılmış atıksuların başlıca kullanım alanları arasında; tarımsal ve yeşil alan sulama, kentsel ve evsel kullanım, endüstriyel kullanım ve yeraltı suyu beslemesi yer almaktadır [6]. Dünya'da geri kazanılmış atıksular \%32 oranında tarımsal sulama amaçlı, \%20 peyzaj amaçlı sulama ve \%19 endüstriyel amaçlı yeniden kullanılmaktadır [7]. Bu bağlamda arıtılmış atık suların geri kazanımı, yeşil alanlarda ve tarımsal sulama amaçlı kullanımı için son yıllarda çalışmalar ve uygulamalar oldukça artmıştır. Atıksuların geri kazanımı konusunda bilinen en eski çalışmalar 1900'lü yıllarda başlamaktadır. Bu ilk uygulamalar; çim ve ağaçların sulanması, tuvaletlerin sifonlarla temizlenmesi, metal sanayinde soğutma suyu olarak kullanım vb. olarak sıralanabilir [8]. Atıksuların uygun bir strateji ile kontrollü olarak tarımda kullanılması, bu suların uzaklaştırılması için etkin bir yöntemdir. Tartışmalı bir konu olmasına rağmen atıksular ile tarımsal sulamanın dünyanın birçok bölgesinde uygulandığı bilinmektedir. Dünyada sulanan tarım arazilerinin 20 milyon ha'nın ham, arıtılmış ve/veya kısmen seyreltilmiş atıksularla sulandığı ifade edilmektedir. ABD ve Porto Riko'da yaklaşık 174 milyon ha tarım alanının yaklaşık 22 milyon ha'ı arıtılmış sularla sulanmaktadır. Florida'da arıtılan suyun toplam hacminin yaklaşık \%19’u, Kaliforniya' da ise yaklaşık \%48'i tarımsal sulama amacıyla kullanılmaktadır [9]. Öte yandan, Berlin, Londra, Milano ve Paris gibi şehirlerde atıksular geri kazanılarak yüzyıllardır tarımda kullanılmaktadır [10]. Ancak son yıllarda su kıtlığı olan bölgelerde atık suların yeniden kazanımı önem kazanmıştır. Pakistan'da ulusal sebze üretiminin \%26'sı için geri kazanılmış atıksular sulama suyu olarak kullanılmaktadır [11] . Gana'da, gayri resmi kayıtlara göre nehirlerden ve akarsulardan seyreltilmiş su ile tarımsal sulama suyu miktarı [12], temiz su ile sulama miktarından daha büyük bir orandır ve alansal olarak tahmini 11.500 ha alanda gerçekleşmektedir [13] Meksika'da yaklaşık 260.000 hektarlık alan, çoğunlukla arıtılmamış atıksu ile sulanmaktadır [14] Atıksuyun yeniden kullanımının başarılı bir şekilde geliştirilmesi, atıksu arıtma tesisinin kurulması, entegre su kaynakları yönetimi, ekonomik, mali analiz ve kamunun kabulü ile yakın ilişkilidir. Öte yandan, atık suların geri kazanımı için ise ikincil arıtımın ötesinde ilave ileri arıtım ve boru hattı şebekelerinin kurulmasına ihtiyaç da duyulmaktadır [15].

Avrupa'da, arıtılmış atık suyun iyileştirilmesine yönelik yasal düzenlemeler bulunmamakla birlikte, sadece Kentsel Atıksu Arıtma Direktifinde "arıtılmış atıksu, uygun olduğunda geri kazanılabilir; tasfiye yöntem(ler)i, çevre üzerindeki olumsuz etkileri minimize etmelidir" ifadesi yer almaktadır. Ancak, Akdeniz Havzasındaki ülkelerden, arıtılmış atıksuyun geri kazanılarak sulamada kullanımı ile ilgili standartları geliştiren ülkeler mevcuttur [16]. Birçok ülke atık suyun yeniden kullanımı uygulamaları için ulusal ya da bölgesel talimatlar veya kılavuz ilkeleri uygulamaktadır. Özellikle suyun yeniden kullanımı için standartlar geliştiren ülkeler arasında Kıbrıs, Fransa, Yunanistan, İspanya, İtalya ve Portekiz gibi ülkeler yer almaktadır. Atık suların arıtılıp yeniden kullanılması ve kullanım alanlarına yönelik çalışmalarda, Avrupa Birliği Direktifleri, Birleşmiş Milletler Çevre Programı ve Çevre Koruma Ajansları tarafından yayınlanan, atık suların yeniden kullanımı, arıtımı, kulanım alanları, potansiyelleri, riskleri ve önlemleri gibi konularını kapsayan kılavuzlar yol göstermektedir [17]. Ülkemizde ise, Avrupa Birliği (AB) uyum süreci kapsamında $\mathrm{AB}$ direktifinin kademeli uyumlaştırılmasına, uygulamasına ve yürürlüğe konmasına yönelik çalışmalar başlatılmıştır. Bu bağlamda, Ulusal Çevre Mevzuatımızda hızla AB Çevre Mevzuatı ile uyumlaştırılarak 20 Mart 2010 tarihinde yayımlanan “Atıksu Arıtma Tesisleri Teknik Usuller Tebliği” 'nde atık suların geri kazanımı ve yeniden kullanımına ilişkin düzenlemeler yer almaktadır [18]. Ülkemizde evsel atıksuların bir su kaynağı, bir hammadde kaynağı ve bir enerji kaynağı olduğu yaklaşımı ile Çevre ve Şehircilik Bakanlığı atıksu arıtma tesislerinde arıtılan atıksuların geri kazanılarak; tarımsal sulamada, yeraltısuyunu beslemede, kentsel amaçla (yeşil alan sulama vb), sulak alanların ve akarsuların beslenerek çevresel/ekolojik amaçlı kullanımı yanında deniz kenarlarında tuzlu su girişimini önleme amaçlı da dahil olmak üzere yeniden kullanımı yolunda hedefini \%5 olarak belirlemiştir. Çevre ve Şehircilik Bakanlığı tarafından desteklenen “Arıtılmış Atıksuların 
Yeniden Kullanımı" Projesinde, 2017 yılında ülkemizde 15 evsel/kentsel atıksu arıtma tesisinden geri kazanılarak yeniden kullanılan suyun oranı \% 0,78 olarak belirlenmiştir. Mevcut olan geri kazanım tesislerinin oranı ise \% 1,2 olarak belirlenmiştir [19].

Atık suların yeniden kullanımı ile hem tatlı su kaynaklarının tüketimi azaltılmakta hem de deşarj edilen arıtılmış atık suların çevresel etkileri en aza indirilmektedir $[17 ; 18]$. Dünyadaki birçok ülke, artan temiz su tedariği baskısı ile karşı karşıyadır ve temiz su kaynaklarının su talebini karşılayamayacak kadar yetersiz hale gelmektedir. Kentsel su kıtlığı artmakta ve su arıtma teknolojisi ilerledikçe, atık sular artan hacimlerde geri kazanılmakta ve dünya çapında daha fazla amaç için atık sular yeniden kullanılmaktadır [20]. Su kıtlığı, çevresel ve ekonomik değerlendirmenin yanı sıra teknoloji iyileştirme olarak atıksuyun yeniden kullanım uygulamalarında itici güç olarak tanımlanabilir [21]. Bu nedenle su kullanımının giderek artması ve yüksek su kalitesi standartlarının karşılanması için arıtma teknolojilerinin geliştirilmesi gerekmektedir [22] Arıtılmış atık suyun geri kazanımı için seçilecek teknoloji; arıtılmış atık suyun özellikleri, geri kullanım amaçları için kalite kriterleri, güvenilirlik, işletme kolaylığı ve ekonomik imkan konuları göz önüne alınarak belirlenmelidir [23]. Dünyada sınırlı bulunan içme ve kullanma suları ile sulanabilen yeşil alanlar için alternatif kaynaklara yönelme zorunluluğu doğmuştur. Alternatif metotlardan biri olan “Arıtılmış Atıksuların Yeniden Kullanımı” bazı ülkelerde olduğu gibi Türkiye’de de yasal düzenleme ile uygulanabilir hale getirilmiştir Bu çalışmada, kentsel atıksuyun ileri arıtma teknolojisi kullanılarak geri kazanımı ve arıtılmış atıksuların yeşil alanların sulamasında yeniden kullanımı amaçlanmıştır.

\section{MATERYAL VE METOT}

Bu çalışmada, kentsel atıksuyun ileri arıtma teknolojisiyle geri kazanımı ve arıtılmış atıksuların yeşil alanların sulamasında yeniden kullanımının uygunluğu belirlenmeye çalışılmıştır. Çalışmanın gerçekleştirilmesinde, İleri Biyolojik kentsel atıksu arıtma tesisi üniteleri, arıtılmış atıksu, geri kazanım tesisi üniteleri, damlama sulama sistemi ve kısıtlanmış yeşil alanlar

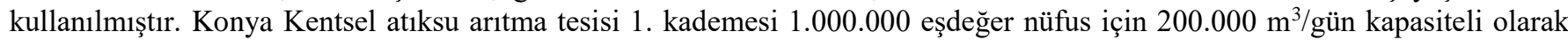
Avrupa Birliği (AB) standartlarında kurulmuş olup, karbon ve kısmi azot giderimine göre ileri biyolojik arıtma metoduna göre tesisin çıkışında UV ile dezenfeksiyon sistemi bulunmaktadır. Arıtılmış atıksuların sulama amaçlı kullanılması planlandığından kısmi Toplam Azot (TN) giderimi tasarlanarak, Toplam Fosfor (TP) giderimi dikkate alınmamıştır. Şekil 1'de İleri Biyolojik Atıksu Arıtma Tesisi (AAT) görülmektedir. Bu çalışma kapsamında, İleri Biyolojik Atıksu Arıtma Tesisinden deşarj edilen arıtılmış atıksuların yeşil alan sulamasında kullanılması amacıyla, $3.600 \mathrm{~m}^{3} /$ gün kapasiteli gerçek ölçekli atıksu geri kazanımı tesisinin performansı izlenmesi çalışması gerçekleştirilmiştir. Şekil 2'de tesisin; Ön Klorlama, Koagülasyon, Multimedya Filtrasyon (MMF), Ultraviyole (UV) Dezenfeksiyon ve Son Klorlama ünitelerinden oluştuğu görülmektedir. Sistem çıkışında arıtılmış atıksuyun yeniden kazanılarak sulama suyu olarak yeşil alanlara iletilmesi için geri kazanılmış atıksu deposu ve 24 km'lik Mor Şebeke boru hatları ile damlama sulama sistemi bulunmaktadır.

Arıtılmış atıksuyu geri kazanmak için kurulan mor şebeke sisteminde bazı su kalite parametrelerinin analiz ve ölçümleri, yeşil alan (park, bahçe vs.) sulamasının özelikle yapıldığı dönem olan Mayıs 2015-Eylül 2015 tarihleri arasında tesisin performansı değerlendirilmiştir.Analizi yapılan parametreler; $\mathrm{pH}$ (Elektrokimyasal Metod SM 4500 H+B), Askıda Katı Madde (AKM, SM 2510 B), Biyolojik Oksijen İhtiyacı (BOİ), Fekal Koliform ve Bakiye Klor, Toplam Katı Madde (TKM; Gravimetrik metod SM 2540 D), Uçucu Katı Madde (UKM, Gravimetrik metod SM 2540 E), Kimyasal Oksijen İhtiyacı (KOİ, Kapalı Reflaks Metodu SM 5520 C), Toplam Organik Karbon (TOK, ISO 8245, ASTM G144, USEPA 415), Toplam Kjeldahl Azotu (TKN, Makro Kjeldahl metodu SM 4500 NB), Protein (SM 4500 NB), Atıksu Debisi (Q, Alan hızı metodudebimetre)'dir. Su kalitesi parametreleri AKM, Bulanıklık, Eİ, BOİ, Fekal koliform laboratuar ortamında Su ve Atıksuların Kontrolü Standart Metotlarına göre analiz edilmiştir [24; 25] Sistemde ölçülen tüm parametreler ve sınır değerleri Atıksu Arıtma Tesisleri Teknik Usuller Tebliği (2010)'ne göre değerlendirilmiştir. 


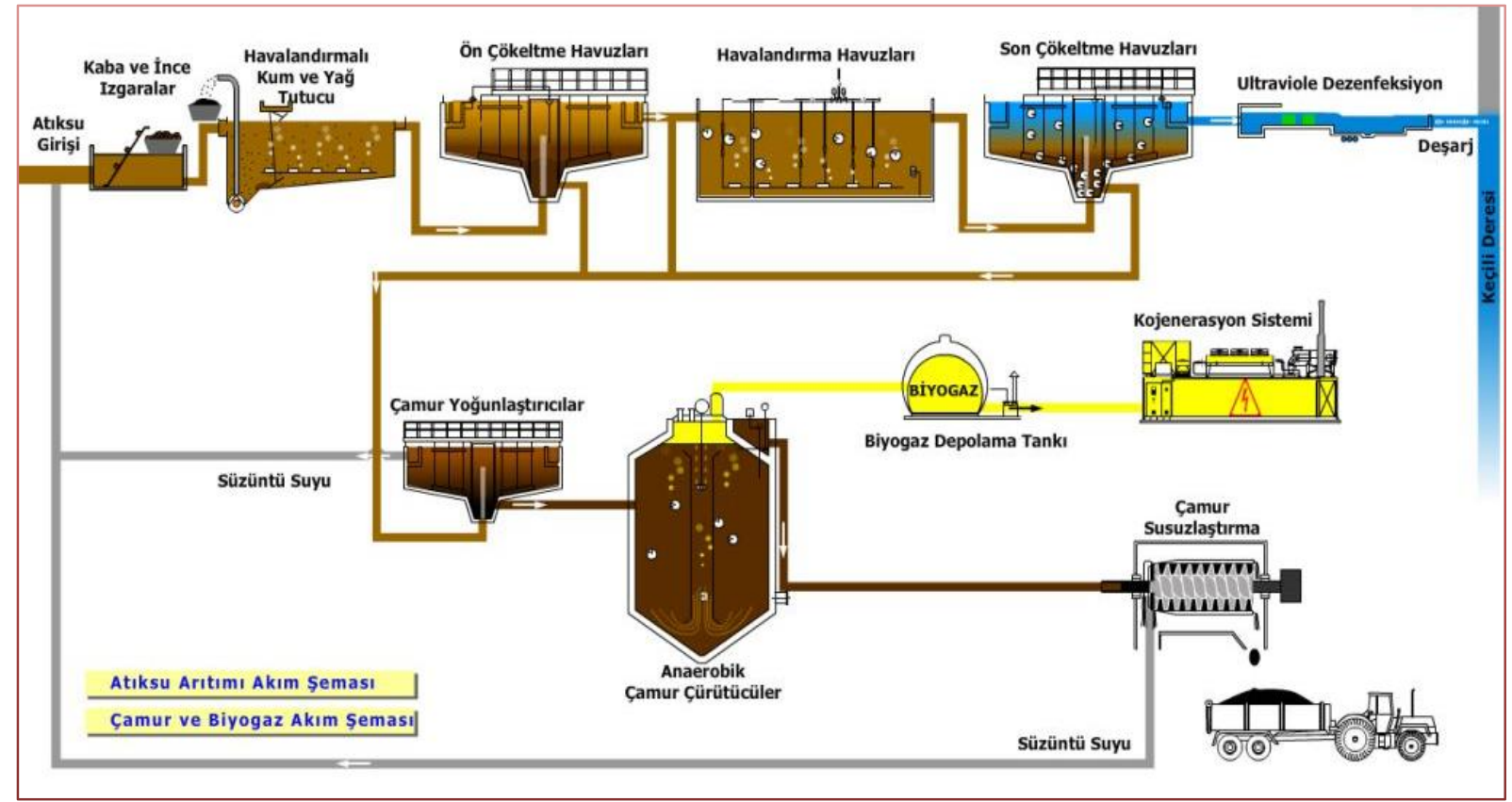

Şekil 1. İleri Biyolojik Kentsel Atıksu Arıtma Tesisi (AAT) Akım Şeması

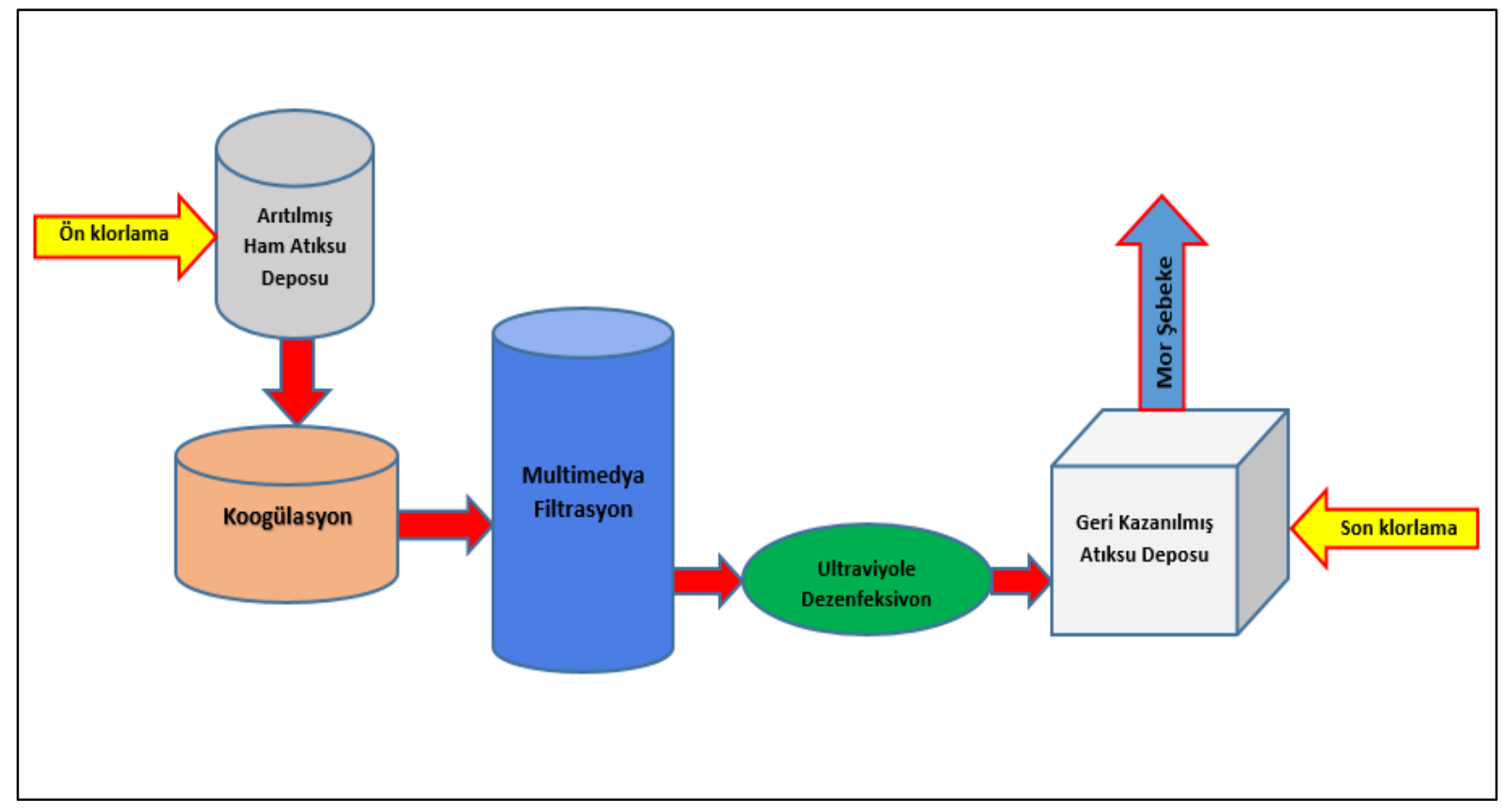

Şekil 2: Atıksu Geri Kazanım Tesisi (AGKT) Üniteleri 


\section{BULGULAR VE TARTIŞMA}

Bu çalışmada, İleri Biyolojik AAT'den deşarj edilen arıtılmış su alınarak, pompayla besiege vasıtası ile mor şebeke sistemine arktarılarak arıtılmış suyun geri kazanımı sağlanmıştır. Geri kazanım tesisinin performansı ve arıtılmış atıksuyun yeniden kullanılabilirliliği, Atıksu Arıtma Tesisleri Teknik Usuller Tebliği (2010)'ne göre değerlendirilmiştir. Bütün verilerin, Türkiye'de geri kazanılmış atıksuların su kalitesi sınıflandırılma kriterlerine (Tablo 1) göre uygunluğu da belirlenmiştir. Bu kapsamda, Multimedya Kum Filtresi (MMF), UV dezenfeksiyon, son klorlama, geri kazanılmış atıksu deposu ve mor şebeke iletim hattında izlenmesi gereken temel kalite parametrelerinden AKM, BOİ, Bulanıklık, Fekal Koliform, Bakiye Klor ve pH değerleri ölçülmüş ve/veya analiz edilmiştir. İleri Biyolojik Atıksu Arıtma Tesisinin çıkışında ortalama AKM 19 mg/l ve ortalama BOİ $21 \mathrm{mg} / \mathrm{l}$ olacak şekilde Atıksu Geri Kazanım Tesisine (AGKT) arıtılmış atıksu olarak alınmaktadır. Geri kazanım proses ünitelerinde işlem gören arıtılmış atıksu, AGKT'nin nihai çıkışında ise ortalama AKM 9 mg/l ve ortalama BOI 10 mg/l olarak belirlenmiştir (Şekil 3 - Şekil 4). Ayrıca, çalışma süresince, tesis giriş ve çıkış ortalama pH değerleri 7,6 -7,7 olarak belirlenmiştir (Şekil 5). Yeşil alan sulaması için üretilen su AKM ve BOİ bazında Atıksu Arıtma Tesisleri Teknik Usuller Tebliği’nde belirtilen (Tablo 1) A ve B sınıfı sulama suyu kriterlerini sağlamaktadır. İleri Biyolojik Atıksu Arıtma Tesisinin AKM ve BOİ giderim verimine paralel olarak geri kazanılan arıtılmış atıksudaki AKM ve BOİ giderimi de artmaktadır.

Tablo 1. Türkiye'de Sulama İçin Arıtılmış Atıksuların Sınıflandırılması [18]

\begin{tabular}{|c|c|c|}
\hline Geri kazanım türü & Aritma tipi & Geri kazanılmış suyun kalitesi \\
\hline \multicolumn{3}{|c|}{ Sınıf A Kentsel Alanların Sulanması } \\
\hline Her türlü yeşil alan sulaması (Parklar, golf sahaları vb.) & $\begin{array}{l}\text {-İkincil aritma } \\
\text {-Filtrasyon } \\
\text {-Dezenfeksiyon }\end{array}$ & $\begin{array}{c}\mathrm{pH}=6-9 \\
\text { BOD }_{5}<20 \mathrm{mg} / 1 \\
\text { Bulanıklık }<2 \mathrm{NTU} \\
\text { Fekal koliform } 0 / 100 \mathrm{ml} \\
\text { Bakiye Klor } \geq 0,5 \mathrm{mg} / \mathrm{l} \\
\end{array}$ \\
\hline \multicolumn{3}{|c|}{ Sınıf B Girişi Kısıtlı Sulama Alanı } \\
\hline Girişi kısıtlı sulama alanı & $\begin{array}{l}\text {-İkincil aritma } \\
\text { - Dezenfeksiyon }\end{array}$ & $\begin{array}{c}\mathrm{pH}=6-9 \\
\text { BOD5 }<30 \mathrm{mg} / \mathrm{l} \\
\mathrm{AKM}<30 \mathrm{mg} / \mathrm{l} \\
\text { Fekal Koliform } \leq 200 / 100 \mathrm{ml} \\
\text { Bakiye Klor } \geq 0,5 \mathrm{mg} / \mathrm{l}\end{array}$ \\
\hline
\end{tabular}

Yeşil alan sulamasında A sınıfı sulama suyu için en önemli parametrelerden biri olan Bulanıklık, geri kazanım prosesinin nihai çıkışında 2,0-4,9 NTU aralıklarında bulunmuştur. (Şekil 6). Bulanıklık parametresi açısından tesisin bazen A sınıfı ve çoğunlukla B sınıfı sulama suyu kriterlerini sağladığı belirlenmiştir. İleri Biyolojik Atıksu Arıtma Tesini çıkışında ortalama

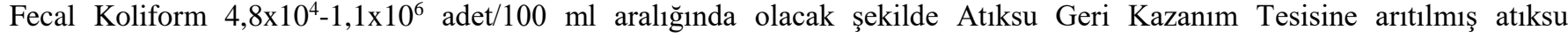
alınmaktadır. Yeşil alan sulamasında en önemli parametrelerden biri olan F. Koliform, geri kazanım prosesinin nihai çıkışında $0 \mathrm{ad} / 100 \mathrm{ml}$ olarak bulunmuştur (Şekil 7). A ve B sınıfı sulama suyu kriterlerine F. Koliform değeri elde edilen sulamaya suyu kriterlerini sağlamaktadır. Bu tür prosesler içinetkili dezenfeksiyon yapılması oldukça önemlidir. Atıksu geri kazanım tesisinde ön klorlama, UV ve son klorlama işlemleri ile etkili dezenfeksiyon sağlandığı görülmüştür. Atıksu Geri Kazanım Tesisinde elde edilen geri kazanılmış atıksu parametre değerleri, prosesin parametre bazında verimleri ve mevzuatta belirtilen sulamaya suyu kriterleri Tablo 2'de verilmiştir. Arıtılmış atıksuyun geri kazanımı sonrasında üretilen çıkış suyu kalitesi Atıksu Arıtma Tesisleri Teknik Usuller Tebliği (2013) göre A sinıfı sulama suyu kriteri olarak belirtilen parametrelerden yalnızca $\geq 2$ NTU olan bulanıklık değerinin proseste, bu kriteri sürekli sağlamadığı belirlenmiştir. Ancak, geri kazanılmış suyun, B sınıfı sulama suyu kriterlerini sürekli olarak sağladığı görülmüştür. 
Tablo 2. İleri Arıtma Tesisinde, AKM, Bulanıklık, BOİ, Fekal Koliform ve Bakiye Klorun Giderim Verimleri

\begin{tabular}{|c|c|c|c|c|c|}
\hline Parametre & $\begin{array}{l}\text { İleri Arıtma } \\
\text { Tesisi Girişi }\end{array}$ & $\begin{array}{l}\text { Klorlama öncesi ve } \\
\text { sonrası, MMF ve UV } \\
\text { dezenfeksiyonu } \\
\text { sonrası oluşan } \\
\text { akışkanlar }\end{array}$ & $\begin{array}{c}\text { Giderim } \\
(\%)\end{array}$ & $\begin{array}{l}\text { Geri kazanılmış } \\
\text { suyun kalitesia }^{\text {a }} \\
\text { Her türlü Peyzaj } \\
\text { Sulama, } \\
\text { Sınıf A }\end{array}$ & $\begin{array}{c}\text { Geri kazanılmış } \\
\text { suyun kalitesia }^{\text {a }} \\
\text { Kısıtlı Erişim } \\
\text { Alanları Sulama, } \\
\text { Sınıf B }\end{array}$ \\
\hline pH & 7,6 & 7,7 & - & $6-9$ & $6-9$ \\
\hline $\begin{array}{l}\text { Bulanıklık } \\
\text { (NTU) }\end{array}$ & 8,8 & 3,4 & 61 & $\leq 2$ & - \\
\hline AKM (mg/l) & 19 & 9 & 53 & - & $\leq 30$ \\
\hline BOİ (mg/l) & 21 & 10 & 52 & $\leq 20$ & $\leq 30$ \\
\hline $\begin{array}{l}\text { Fekal Koliform } \\
(\text { CFU/100 ml) }\end{array}$ & $4,5 \times 10^{5}$ & 0 & 100 & 0 & $\leq 200$ \\
\hline $\begin{array}{l}\text { Bakiye Klor } \\
\left(\mathbf{m g} / \mathbf{l ~ C l} \mathbf{l}_{2}\right)\end{array}$ & - & 0,6 & - & $\geq 0,5$ & $\geq 0,5$ \\
\hline
\end{tabular}

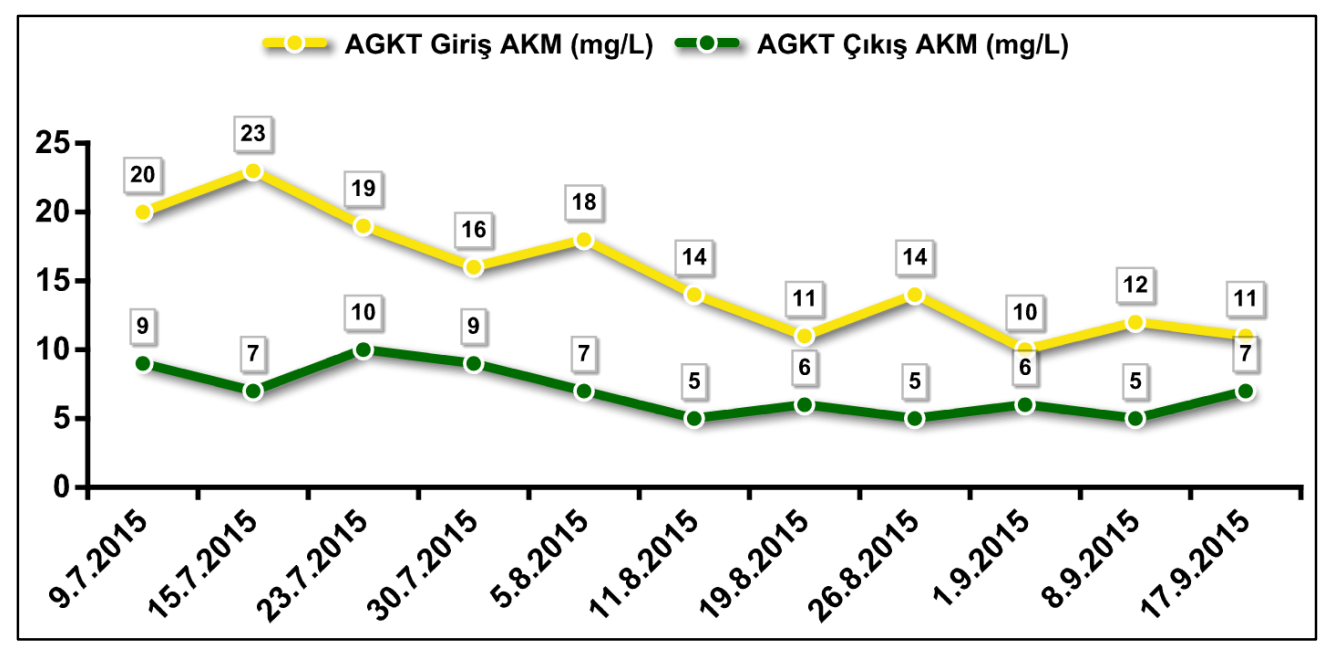

Şekil 3. AGKT Giriş-Çıkış AKM Konsantrasyonları

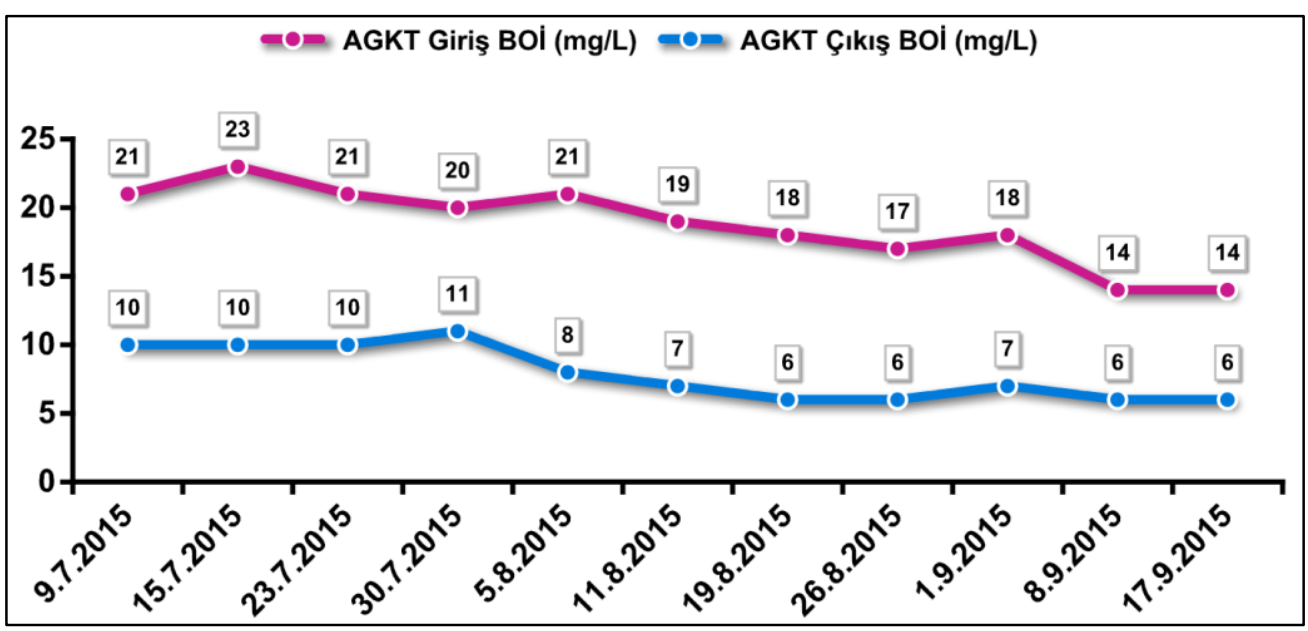

Şekil 4. AGKT Giriş- Çıkış BOİ Konsantrasyonları 


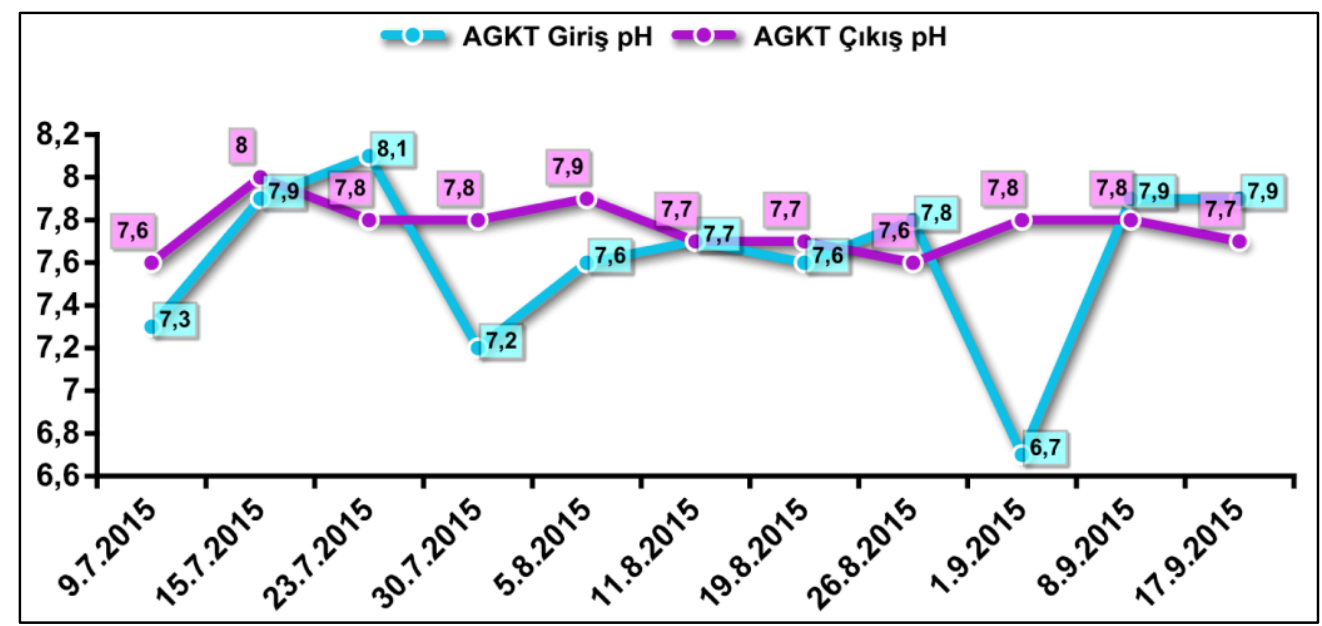

Şekil 5. AGKT Giriş- Çıkış pH Değerleri

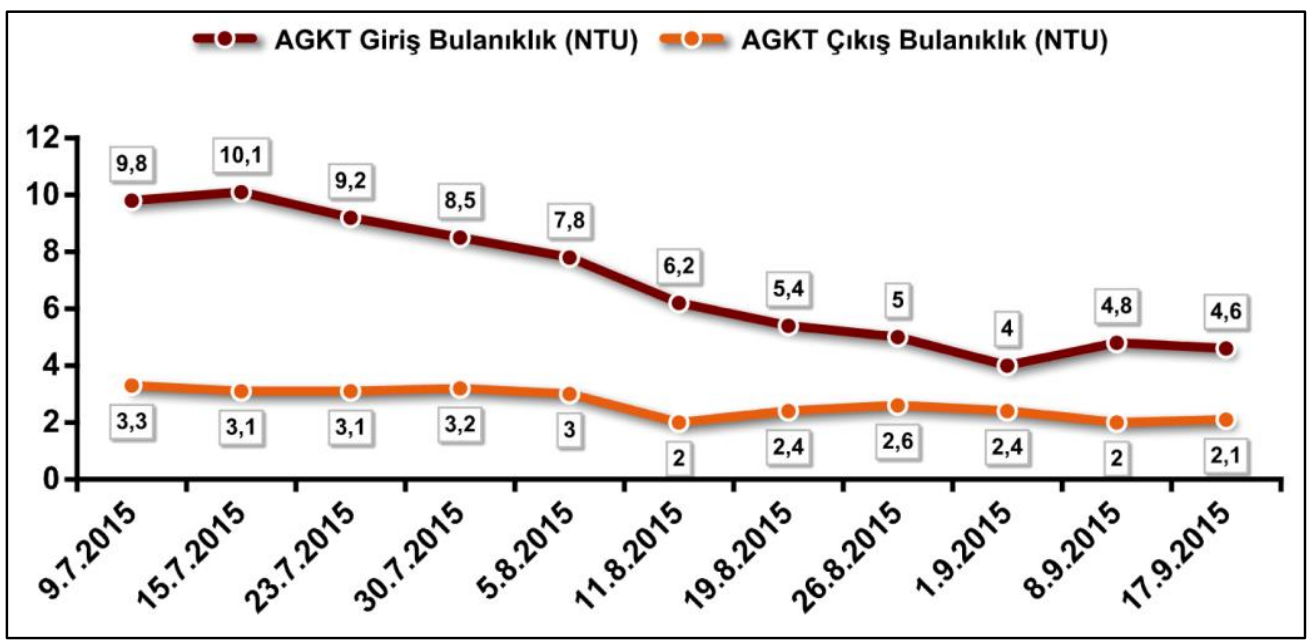

Şekil 6. AGKT Giriş- Çıkış Bulanıklık Değerleri

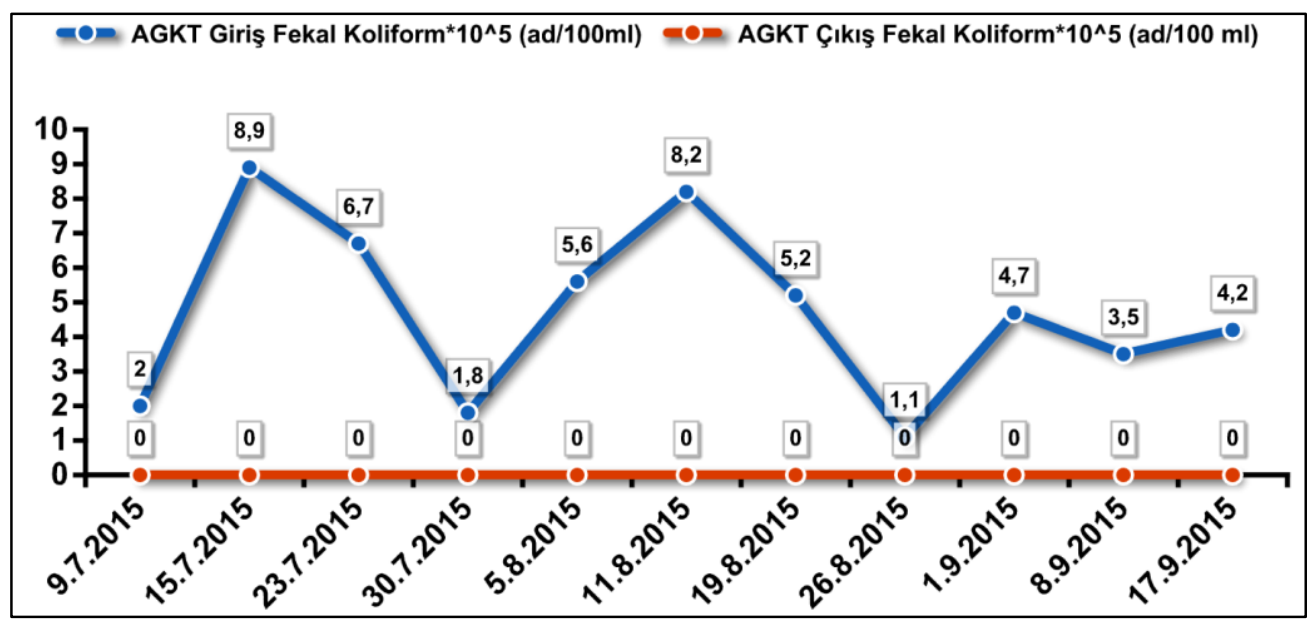

Şekil 7. AGKT Giriş- Çıkış Fekal Koliform Değerleri 


\section{SONUÇLAR}

$\mathrm{Bu}$ çalışmada, gerçek ölçekte arıtılmış atıksuyun Geri Kazanım Tesisinin çıkış suyu kalitesi ve performansı izlenerek, parametreler bazında verimlilikleri; \% 53 AKM, \%52 BOİ, \% 61 Bulanıklık, \%100 F. Koliform olarak belirlenmiştir. Atıksu geri kazanım tesisinin çıkış suyu kalitesi ve performansının tamamen ileri biyolojik atıksu arıtma tesisinin performansına bağlı olarak değiştiği belirlenmiştir. Geri kazanılmış atıksu ile yeşil alan sulaması uygulaması için en önemli kalite parametreleri olan patojen mikroorganizmaların tamamen giderilmesi ve nihai noktada bakiye klorun $\geq 0,5 \mathrm{mg} / \mathrm{l}$ ve $\mathrm{pH} \mathrm{kriterlerinin}$ sürekli sağlandığı görülmüştür. Bu çalışmada, arıtılmış atıksuların geri kazanımı sağlanarak, sulama sezonunda yıllık ortalama 385.000 $\mathrm{m}^{3}$ su ile yaklaşık $3.300 .000 \mathrm{~m}^{2}$ yeşil alan sulaması yapılmıştır. Ayrıca, arıtılmış atıksuların yeniden kullanılmasıyla mevcut su kaynakları korunmasına yönelik su ihtiyacını karşılamak için yeni bir kaynak olarak da kullanılabilirliliği uygun bulunmuştur. Sonuç olarak, bu çalışmada yeşil alanların sulaması için içmesuyu şebeke suyu yerine arıtılmış atıksuların geri kazanılması sağlanarak, su kaynaklarının korunması ve sürdürülebilir su/atıksu yönetimi yaklaşımı gerçekleştirilmeye çalışılmıştır. Öte yandan mevcut atıksu geri kazanım prosesinde, A sınıfı sulamaya suyu elde edilebilmesi için mevcut tesise aktif karbon adsorpsiyonu, ileri filtrasyon ve/veya membran ünitelerinin ilave edilmesi ile tarımsal amaçlı ve endüstrinin kulanımına uygun su elde edilmesi sağlanabilir.

\section{TEŞEKKÜR}

Bu çalışmaya teknik ve mali destek sağladığg için Konya Büyükşehir Belediyesi Su ve Kanalizasyon İdaresi Genel Müdürlügüü'ne (KOSKİ) çok teşekkür ederiz.

\section{KAYNAKLAR}

[1] M. Qadır, D. Wichnels, L. Raschid-Sally, P. Singh M. P. Drechsel, A. Bahri and P. Mccornick, "Agricultural use of marginal-quality water-opportunities and challenges. In: Molden, D. (Ed.), Water for Food; Water for Life. A Comprehensive Assessment of Water Management in Agriculture", Earthscan, 8-12 Camden High Street, London, pp. 425-457, 2007.

[2] I. A. Alaton, A. Tanık, S. Övez, G. İskender, M. Gürel and D. Orhon, "Reuse potential of urban wastewater treatment plant effluent in Turkey: a case study on selected plants”, Desalination, vol. 215, pp. 159-165, 2007.

[3] Kalkınma Bakanlığı, Onuncu Kalkınma Planı (2014-2018), Ankara, 2013

[4] A. U. Öktem and A. Aksoy, "Türkiye'nin Su Riskleri Raporu”, WWF-Türkiye, Ofset Yayınevi, İstanbul, 2014.

[5] B. Ekinci, "Su Kaynaklarının Verimli Kullanılmasına Yönelik Örnek Ülke Uygulamaları ve Ülkemizde Bu Çalışmaların Uygulanabilirliliği”, Ankara, 2015.

[6] P. Ayben, "Su Kaynaklarının Sürdürülebilirliği İçin Arıtılan Atıksuların Yeniden Kullanımı”, Türk Bilimsel Derlemler Dergisi, vol. 1, pp. 58-62, 2013.

[7] Environmental Protection Agency (EPA), “Guidelines for Water Reuse. EPA/600/R-12/618”, Washington, D.C., 2012

[8] T. Asona, "Water from (waste) water- the dependable water resource", The 11th. Stockhlom Water Symposium, Stocklom, Sweden, pp. 12-18, 2001.

[9] USEPA, Guidelines for Water Reuse, EPA/625/R-04/108, September, U.S. Agency for International Development, Washington, DC, 450, 2004.

[10] Australian Academy of Technological Sciences and Engineering (AATSE), Water Recycling in Australia, Victoria, Australia, 2004.

[11] H. H. Ensink, T. Mehmood, W. Vand Der Hoeck, L. Raschid-Sally and F. P. Amerasinghe, "A nation-wide assessment of wastewater use in Pakistan: an obscure activity or a vitally important one?”, Water Policy, vol. 6, pp. 197-206, 2004.

[12] T. V. Lai, Perspectives of peri-urban vegetable production in Hanoi. Background paper prepared for the Action Planning Workshop of the CGIAR Strategic Initiative for Urban and Peri-urban Agriculture (SIUPA), Convened by International Potato Center (CIP), Lima. Hanoi, 2000.

[13]B. N.Keraita and P. Drechsel, Agricultural use of untreated urban wastewater in Ghana. In: Scott, C.A., Faruqui, N.I., Raschid-Sally, L. (Eds.), Wastewater Use in Irrigated Agriculture. CABI Publishing, Wallingford, UK, 2004.

[14] C. Mexico, Water Statistics, National Water Commission, Mexico City, 2004.

[15] T. Asano, F. L. Burton, H. L. Leverenz, R. Tsuchıhashı and G. Tchobanoglous, Water Reuse: Issues, Technologies, and Applications, First Ed. McGraw-Hill, New York, 2007.

[16]F. Brissaud, "Criteria for water recycling and reuse in the Mediterranean countries", Desalination, vol. 218, pp. 24-33, 2008. 
[17] L. Pint11e, C. M. Torres, C. Teodosiu and F. Castells, "Urban wastewater reclamation for industrial reuse: An LCA case study", Jounral of Cleaner Production, vol. 139, pp. 1-14, 2016.

[18] Atıksu Arıtma Tesisleri Teknik Usuller Tebliği (AATUT), RG/27527, 2010.

[19] B. Nas, Arıtılmış Atıksuların Yeniden Kullanımı Projesi, Çevre ve Şehircilik Bakanlığı \& Selçuk Üniversitesi, Final Raporu, Ankara, 2018.

[20] A. D. Levine and T. Asano, "Recovering sustainable water from wastewater", Environmental Science Technology, vol. 38, no. 11, pp. 201-208, 2004.

[21] L. Sidan, C. Weipıng, Z. Weılıng, F. Yupeng, and J. Wentao, J., "Wastewater reclamation and reuse in China: Opportunities and challenges", Journal of Environmental Sciences, vol. 39, pp. 86 - 96, 2016.

[22] A. Hurlımann, D. Hes, M. Othman and T. Grant, "Charting a new course of water is black water reuse sustainable", Water Science Technology Water Supply, vol. 7, pp. 109-118, 2007.

[23] N. Büyükkamacı, "Su Yönetiminin Etkin Bileşeni:Yeniden Kullanımı, İzmir Kent Sorunları Sempozyumu”, İzmir, pp. 363-377, 8-10, 2009.

[24] APHA/AWWA/WEF, Standard Methods for the Examination of Water and Wastewater. American Public Health Association/American Water Works Association/Water Environment Federation, 21th edition, Washington DC, USA, 2005.

[25] EPA, Environmental Protection Agency Guidelines for Water Reuse, EPA/625/R-04/108, 2004. 